\title{
Geometrical optic learning difficulties for Moroccan students during secondary/university transition
}

\author{
Naoual Nasser ${ }^{1}$, El Mostapha El Khouzai ${ }^{2}$, Abdallah Zahidi $^{3}$ \\ ${ }^{1,2}$ IR2M Laboratory, Didactic Engineering and Systems Dynamics Team, Faculty of Science and Technology, \\ Hassan First University, Morocco \\ ${ }^{3}$ Optics Laboratory, National Institute of Post and Telecom, Morocco
}

\begin{tabular}{l} 
Article Info \\
\hline Article history: \\
Received Apr 2, 2020 \\
Revised Nov 24, 2020 \\
Accepted Jan 26, 2021 \\
\hline
\end{tabular}

\section{Keywords:}

Difficulties learning

Geometrical optics

Moroccan students

Transition

\begin{abstract}
To remedy the difficulties encountered by Moroccan students in geometrical optics during the transition from secondary to higher education and for an efficient education system, we propose this study to investigate the causes of these difficulties as well as their impact on the quality of the secondary/university transition, and come up with a remediation device to overcome them. For this survey, we adopted a mixed method to collect both qualitative and quantitative data. The research tools used are semi-directive interviews with thirty high school and university teachers; questionnaires and exercises were administered to 120 of first year university students. The results of this study revealed the persistence of difficulties in geometrical optics and particularly in geometric construction whose origins are attributed to the misrepresentations and low prerequisites among students as well as a break in the curriculum and teaching methods during the transition from secondary to higher education.
\end{abstract}

This is an open access article under the CC BY-SA license.

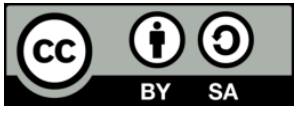

\section{Corresponding Author:}

Naoual Nasser

IR2M Laboratory, Didactic Engineering and Systems Dynamics Team

Faculty of Science and Technology

Hassan First University

Road to Casablanca Km 3.5 Hassan First University, BP 539, Settat, Morocco

Email: nasser.naoual@hotmail.com

\section{INTRODUCTION}

The education and training system aspires to advance the country in the conquest of science and the mastery of advanced technologies. It thus contributes to strengthening its competitiveness and its economic, social, and human development. It also ensures the qualification of graduates' skills to enter professional life. The qualification consists of a set of attitudes, knowledge, and students' skills that must be reached at the basic and middle education institutions [1]. This qualification is ensured, among other things, by the understanding of the concepts. This conceptual understanding has become a growing interest in Physics Education Research. Many previous researchers have reported that in Morocco, as in other educational systems, physical science (PS) learning presents many difficulties for almost all learners of all school levels [1-6]. In higher education (HE), major shortcomings in the teaching of this discipline are often manifested by a very low level of motivation among students, resulting in a decrease in the number of new students and a lack of qualitative understanding of the PS basic concepts after teaching [7].

The geometrical optics (GO) constitutes a branch of the PS which is based on the light ray (LR) model characterized by a variety of concepts, it allows the geometrical construction (GC) of images; that is why it is called the GO. It also explains the formation of images and studies the macroscopic effects of the 
optics such as the rectilinear propagation of light, reflection, and refraction. GO learning poses serious problems for students [8-10]. Moreover, research shows that learners usually keep a lower level of understanding concepts without any relation to the GO scientific concepts (SC) and that this significant phenomenon even persists at HE [10-12]. The majority of these difficulties concern light and its properties, vision as well as the formation of the image [13]; hence, the learner's inability to provide scientific explanation and apply reasoning in far more complicated contexts [8].

In Morocco, the educational system comprises a three-year pre-school, six-year primary, three-year middle school, three-year qualifying secondary, which includes the common core, the first and the second years of the baccalaureate (bac), along with the HE levels. For all these school levels, each year consists of two semesters. The evaluation system, in this case in scientific fields at secondary education (SE), is based on continuous assessment for the passage of the common core to the 1 st year of bac, and the regional examination in secondary subjects with the marks of the continuous assessment for the passage of the 1st year to the 2 nd year of bac. At the end of SE, students are required to pass a national examination to obtain the bac certificate.

As in other countries, Moroccan HE students still encounter a difficulty to grasp some basic concepts in optics even after a whole semester of teaching [14]; they do not correctly conceptualize the formation of the image by a mirror [15]. Therefore, in this study the authors reckoned that it was necessary to elucidate the causes of GO difficulties and examine their impact on the quality of the SE/HE transition in order to achieve the highest quality of the GO teaching and learning $(\mathrm{T} / \mathrm{L})$ at HE. A careful reading of the literature allowed us to identify the main factors responsible for the GO difficulties observed during SE and HE. Among these factors we find the misrepresentations, the low prerequisites, the teaching methods (TMs), and the curriculum.

According to this literature $[16,17]$, the students' misrepresentations are deemed of as a major factor responsible for GO difficulties. Indeed, researchers have proven that during the process of T/L, as has always been observed, that students from primary school to HE build their ideas about the light of their daily life experiences, which is usually contradictory to PS laws $[8,12,18]$. These misrepresentations persist and resist change even though students have successfully developed SC [14, 19]. The possession of these misrepresentations which are often shared by students of almost all levels [13] and from different countries are most likely to prevent them from understanding and developing SC; which influences their learning $[20,21]$. The majority of the GO misrepresentations are related to three basic concepts: light, image, and vision [22].

The light: Students have misrepresentations concerning the LR [11]. They may very well use the word (ray) without attributing to it the meanings that constitutes the corresponding SC. They also consider rays as real physical objects; they believe that a luminous object produces parallel rays that travel through space in the horizontal direction [3, 17, 23, 24].

The vision: Some students explain vision by the eyes which send something like gazing or rays $[25,26]$, and they generally cannot demonstrate the link between the eye and a visualized image. They believe that it suffices to look at an object to see it $[8,24,27]$, they also think that light is visible even if it doesn't penetrate in the eyes of the observer [28] and that light is not necessary to see [29].

The image: Learners believe that the image of an object could be projected onto a screen without lens [13, 22, 23], and a half-lens produces a half-image [8]. They also believe that the convex lens shows the object thin and concave lenses thick [13]. Some students think also that they would be able to see more of themselves in a mirror by moving further away [30] and a plane mirror (PM) forms a real image [31].

In addition to the misrepresentations that distinguish students, they lack the necessary prerequisites that enable them to perceive certain basic knowledge in GO [14]. Some studies have found that these basic prerequisites are not well constructed during SE [32,33], and that they are characterized by a fragility that makes students unable to explain physics phenomena. What's more, certain notions aren't well mastered at HE by students like the formation of an image by a lens despite having been dealt with during SE [23]. In the same token, other researches show that students are incapable of materializing an LR and generally identifying the rectilinear propagation of light $[3,18]$ and they find it difficult to differentiate the real image from the virtual. This is what influences their ability to form an image from the reflection and the refraction of the light [34], and affecting, therefore, the conventional geometrical techniques of the construction of images [35].

Concerning the TMs, at SE, teachers adopt inadequate TMs attitudes in interacting with their students [36] particularly in GO as they use inappropriate LR during imagery and produce unclear schemes [11]. According to Frédéric \& Boudaoné [11]; and Douar [37], the didactic transposition that would allow students to give meaning to the concepts taught in optics and guarantee a good continuity of knowledge between SE and HE is inappropriately undertaken. What's more, practical works (PWs) which is regarded as primordial school activities destined to consolidate knowledge in SE, fail to promote its assigned objectives 
due to its traditional characteristics [7, 37]. In addition, the teachers' inability to provide and master the materials [38] affects the learning of students [11]. As in several worldwide universities, the PS teaching in the Moroccan university still keeps traditional characteristics since a large amount of knowledge is transmitted by the teacher through the magisterial courses [21]. These TMs seems insufficient to allow a good understanding of physical concepts, and a serious gap is created between what is traditionally taught and what students have to learn more particularly in the first years of HE [39]. An interesting study found a significant relationship between the learning styles and the teaching styles, because they can either increase or decrease students' academic performances [40]. In these seemingly traditional TMs, the PWs that apparently implements theoretical knowledge via application [41] and develops experimental skills as well as students' motivation for the study of PS are also traditional [14]. Regarding the use of the information and communication technologies (ICTs), researchers have confirmed that their integration in PS teaching is insufficient [42]. On the other hand, some researchers showed that there is a high perception of students while using ICTs during the process of T/L at HE [43].

Concerning the last factor related to the curriculum, researchers note that some studies point out that the Moroccan educational system continues to face certain serious challenges such as the shortage of qualified teachers, lack of adapted curricula, and absence of a unified curriculum [44]. Other studies have shown that Moroccan SE students face three principal problems: the complexity of SC, the rapid forgetting of the acquired notions and the overloaded program. They add another serious problem most notably that of the difficulty to assimilate the optic concepts $[45,46]$. Moreover, SE is conditioned by the school text books required by the ministry of national education (MEN) [46]. In these text books, the eye is mentioned within an optical device's context together with other optic instruments. The role of the observer which is crucial to understand optic phenomena remains secondary. The necessity to convince the learner that optic understanding is based on the penetration of light in the eye so that vision can take place is often ignored in the school text book instructions $[8,47]$. Also, the terminology used in these books as well as by teachers can cause problems; for example, the use of "thin edge lens" instead of a convex lens and the expression "thick edge lens" instead of the concave lens [13]. As for the HE programs, it is characterized by its scholarly knowledge, which presents enormous difficulties for many students accustomed to a SE program based on a didactic transposition to be a teachable knowledge [46].

The Moroccan HE is characterized by a massive repetition in the first year at the university which has been accentuated since 2010-2011 [48]. Moreover, since the adoption of the license, master, doctorate (LMD) system, no global evaluation has been done to identify students' acquired knowledge so that they can be capitalized and remedied within the limits and the difficulties arisen during its implementation, especially at the level of scientific fields in open-access institutions [48].

According to an unpublished statistics related to the results of diagnostic evaluations carried out by a group of teachers at the Regional Centre for Education and Training Professions (CRMEF) CasablancaSettat, whose vocation is to train future PS teachers in SE holder of a License in PS, it can be seen that $80 \%$ of trainee teachers had grades that are inferior to $5 / 20$ in GO; while more than $76 \%$ among them had marks that are superior of 14/20 in electricity and mechanic. Also, the above literature has raised the causes of the GO difficulties encountered in each level of education. But the research that treats the correlation between the SE/HE transition and the failure of first-year university students in GO are scarce.

The school transition is defined as a process of change from one level to another. In fact, it constitutes a great moment of transformation in the educational environment [49]. This matter of transition between the two levels of education was the main subject of many studies throughout the globe under varied perspectives and aspects [50-52]. Indeed, this is the reason why we are interested in this present work. A mixed-method was adopted to collect quantitative and qualitative data to evaluate the quality of the representations and the prerequisites among Moroccan students, the continuity of the TMs adopted, and programs between the two levels of education along with verifying the impact of these elements on the quality of the SE/HE transition. Finally, researchers tried to suggest a remediation device that is capable of overcoming these difficulties.

\section{RESEARCH METHOD}

As has been noted earlier, the objective of our survey is to evaluate the quality of the representations together with the prerequisites among Moroccan students, the continuity of the TMs adopted, and the programs between the two levels of education. It also aims to verify the impact of these elements on the quality of the SE/HE transition. Researchers adopted a mixed method to collect qualitative and quantitative data for the academic year 2016/2017. The target population concerned first year Moroccan university students with a sample of 120 students from Hassan I and Hassan II University (aged from 18 to 21), 30 PS teachers whose work experience exceeds 15 years, seventeen SE teachers, and 13 HE teachers. This study 
relied on a randomly selected population which belongs to the region of Casablanca-Settat. The research tools were questionnaire, exercises, and semi directive interviews. The two self-administered questionnaires were given at the same time to students before teaching GO and they included closed questions related to the sources of the GO difficulties. The final version of these questionnaires has been validated by two PS professors from the CRMEF Casablanca-Settat in addition to one PS pedagogical inspector and three PS teachers practicing in the SE after writing and correcting a test version. The purpose of these questionnaires are to evaluate their representations and their prerequisites related to light propagation, vision, converging lenses (CLs), PM, and prism. Two weeks after teaching this lesson, three exercises to evaluate the students' level at GC were distributed with our presence to provide them with more explanation and guidance, so that they can solve these exercises. All exercises are related to the GC of the image respectively by PM, refraction and by the CLs. The collected data was processed and analyzed using Excel software.

The semi directive interview used to collect qualitative data orally from teachers was adopted after choosing the content of the interview guide. In this case, the themes are related to the GO difficulties, students' misrepresentations, the programs, and the TMs adopted as well as the solutions to overcome them and ensure a successful SE/HE transition. The data from this individual interview, carried out by note-taking, was transcribed and analyzed horizontally in the form of a table.

\section{RESULTS AND DISCUSSION}

\subsection{Teachers' responses}

Table 1 shows the SE and HE teachers' responses related to the GO difficulties, students' misrepresentations, programs, and the TMs adopted as well as the solutions to overcome them. These responses are collected according to a semi directive interview.

Table 1. SE and HE teachers' responses for the semi directive interview

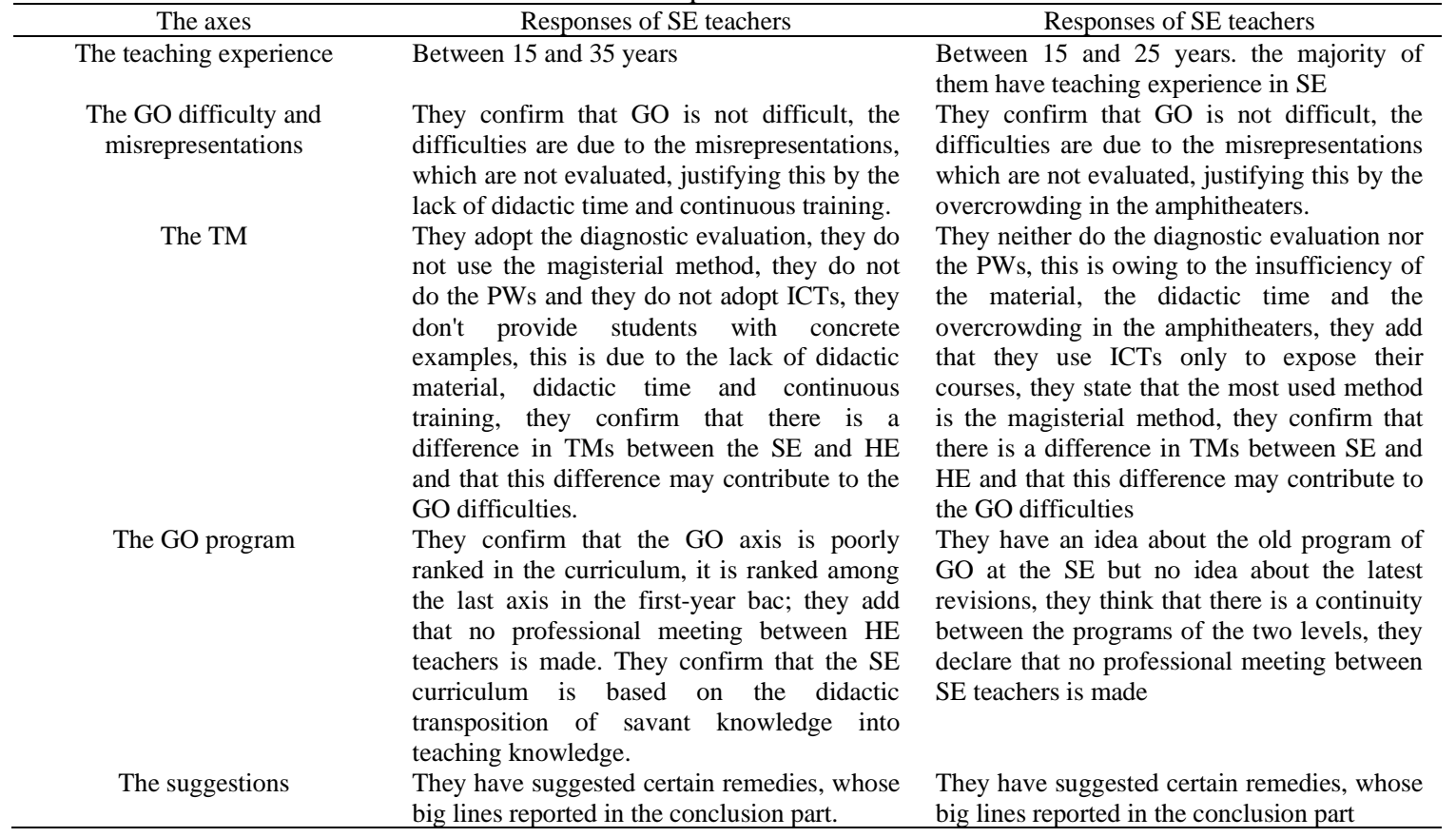

\subsection{Students' answers to the first questionnaire at the beginning of the GO course}

Figure 1 illustrates the students' responses related to the sources of GO difficulties. These responses to the first questionnaire are collected at the beginning of the GO course. 


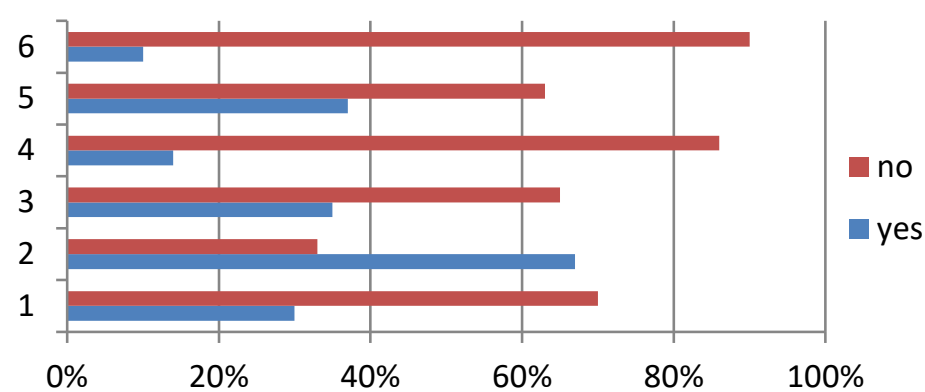

Figure 1. Students' responses to the first questionnaire related to the sources of GO difficulties

With the numbers from 1 to 6 in the vertical axis of Figure 1 corresponds to

1: Do you think that you can succeed in the GO?

2: Do you find GO difficult?

3: Have you done the GO course in the first-year bac?

4: Has your prerequisites been evaluated at the beginning of the GO course?

5: Do you find the GO useful for you?

6: Your representations were raised and corrected at the beginning of the GO course?

\subsection{Students' answers to the second questionnaire at the beginning of the GO course}

Figure 2 to Figure 5 highlight the Students' answers to the second questionnaire at the beginning of the GO course. This questionnaire was administrated to the students in order to evaluate their prerequisites and representations related to the CLs, relations of conjugation, light propagation, vision, PM and prism.

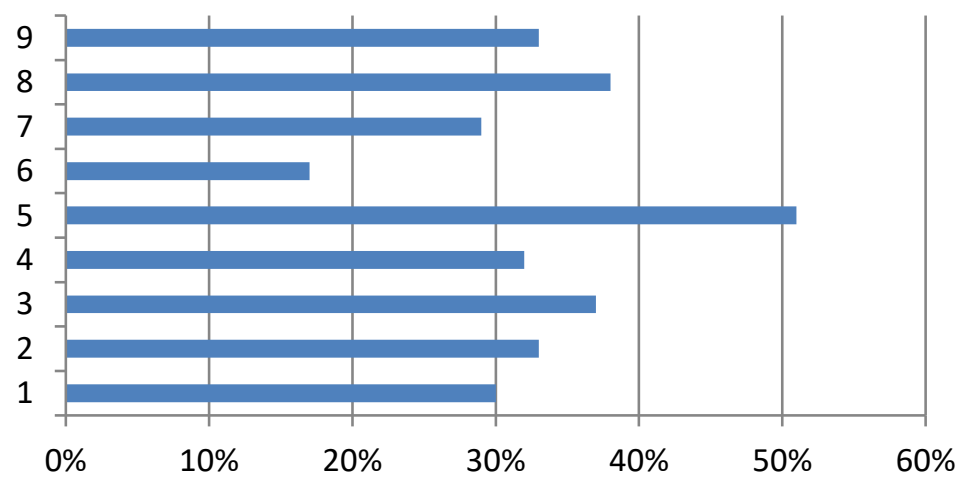

Figure 2. Students' answers concerning the formula of conjugation relations, functions and proprieties of CLs

With the numbers from 1 to 9 in the vertical axis of Figure 2 corresponds to

1: Any incident light ray passing through the principal focus object of the CL cannot be deviated

2: Any incident light ray passing through the optical center of the CL will be deviated

3: Any incident light ray passing through the principal focus object of the CL emerges parallel to its main optical axis.

4: The CLs are lenses with thin edges

5: The CLs are lenses with thick edges

6: The CLs are Lenses with thin and thick edges

7: The formula for conjugation relations is: $\frac{1}{\overline{\mathrm{OA}^{\prime}}}-\frac{1}{\overline{\mathrm{OA}^{\prime}}}=\frac{1}{\overline{\mathrm{OF}^{\prime}}}$

8: The formula for conjugation relations is: $\frac{1}{\overline{\mathrm{OA}^{\prime}}}-\frac{1}{\overline{\mathrm{OA}}}=\frac{1}{\overline{\mathrm{OF}^{\prime}}}$

9: The formula for conjugation relations is: $\frac{1}{\overline{\mathrm{OA}^{\prime}}}-\frac{1}{\overline{\mathrm{OA}}}=\frac{1}{\overline{\mathrm{OF}}}$ 


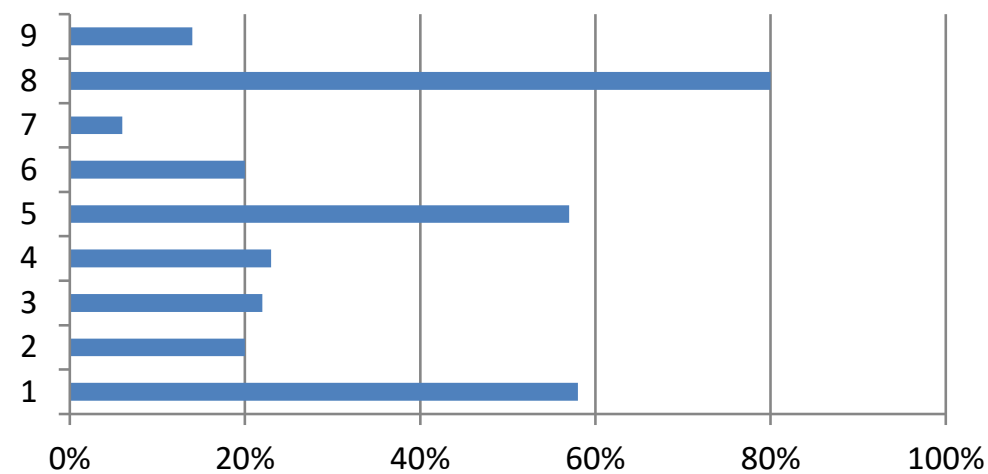

Figure 3. The students' answers about their representations related to the light propagation and vision

With the numbers from 1 to 9 in the vertical axis of Figure 3 corresponds to

1: Light propagates according to the horizontal direction

2: Light propagates according to the vertical direction

3: Light propagates along the straight lines in the space

4: To see an object the eyes must send rays

5: To see an object it is enough to look at it to see it

6: To see an object, is necessary that the light reflected by the object must penetrate the eyes of the observer

7: We can see in a dark room

8: We cannot see in a dark room

9: We can see a little in a dark room

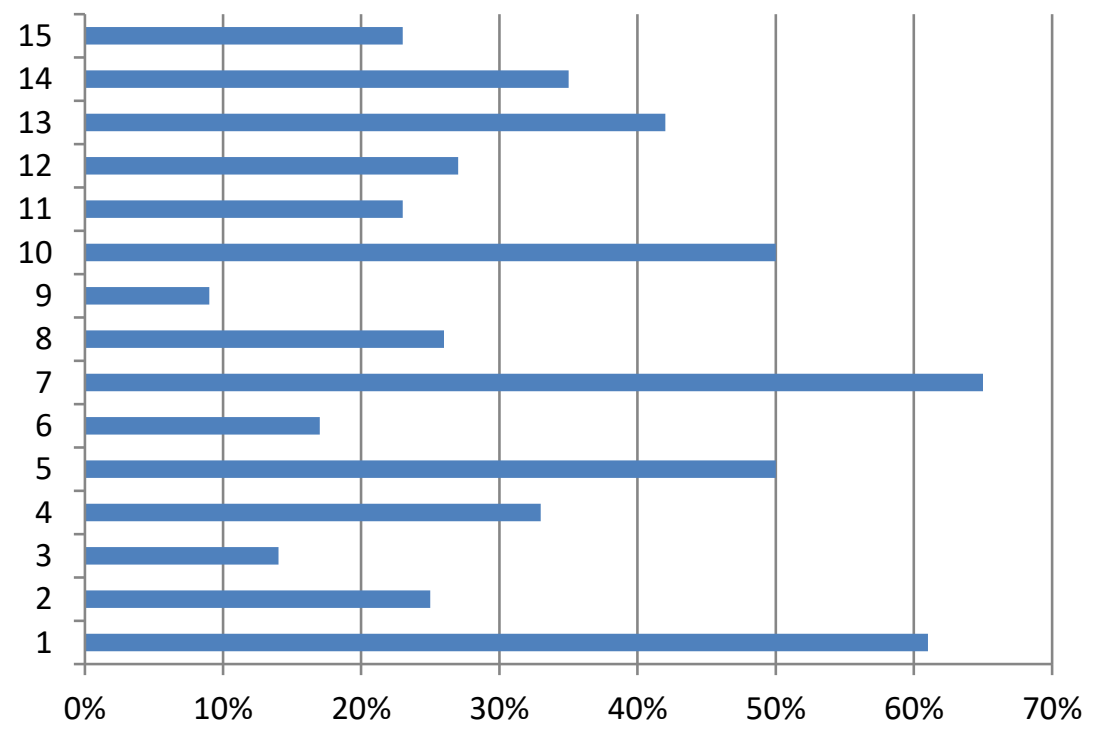

Figure 4. Students' answers about the reflection by a PM, the formula for Descartes' 2nd law of refraction and the dispersion of light by a rectangular prism

With the numbers from 1 to 15 in the vertical axis of Figure 4 corresponds to

1: The obtained image by the PM is real

2: The obtained image by the PM is Virtual

3: I don't know the nature of the image obtained by PM

4: Figure 5a1 is the correct answer about GC of image by PM

5: Figure $5 \mathrm{a} 2$ is the correct answer about GC of image by PM

6: Figure $5 \mathrm{a} 3$ is the correct answer about GC of image by PM

7: To see more of themselves in a mirror by moving further away 
8: To see more of themselves in a mirror by moving closer away

9: To see more of themselves in a mirror by moving to the right or the left

10: Figure $5 \mathrm{~b} 1$ is the correct answer about the dispersion of light by a rectangular prism

11: Figure $5 \mathrm{~b} 2$ is the correct answer about the dispersion of light by a rectangular prism

12: Figure $5 \mathrm{~b} 3$ is the correct answer about the dispersion of light by a rectangular prism

13: The formula for Descartes' 2 nd Law of refraction is: $n_{1} \cdot \operatorname{SinI} I_{1}=n_{2} \cdot \operatorname{SinI}_{2}$

14: The formula for Descartes' 2 nd Law of refraction is: $\mathrm{n}_{1} \cdot \operatorname{SinI} \mathrm{S}_{2}=\mathrm{n}_{2} \cdot \operatorname{SinI}_{1}$

15: The formula for Descartes' 2 nd Law of refraction is: $\mathrm{n}_{1} \cdot \operatorname{SinI}_{1}=\mathrm{n}_{2} \cdot \operatorname{SinI}_{1}$

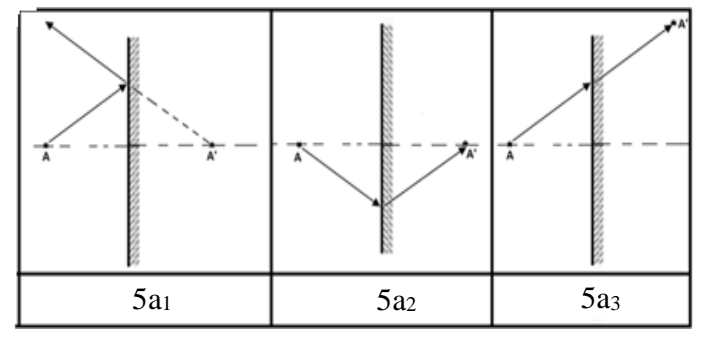

(a) The GC of an image by a PM

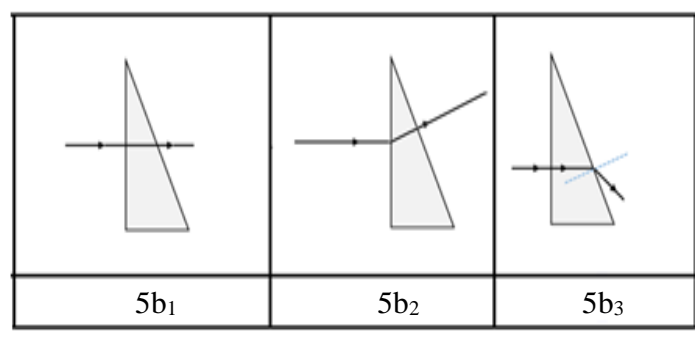

(b) The dispersion of light by a rectangular prism

Figure 5. The testing administrated to the students

From the Table 1, the obtained results show that teachers adopt traditional TMs which do not involve students who are deemed of as the core of the T/L process in the construction of knowledge. What's more, they do not resort to the learner's environment while giving examples in GO. Besides, they do not do concrete PWs to apply theoretical knowledge. The HE teachers adopt the magisterial method without any sort of interaction with students due to the overcrowding of the lecture halls and the insufficiency of the didactic time, which leads to a discontinuity in the TMs between SE and HE. All these conditions do not promote a good transition and, therefore, accentuate GO difficulties for first year university students.

According to Figure 1, there are $67 \%$ of students consider GO is difficult and $70 \%$ of them confirm that they cannot succeed. The teachers surveyed have a different opinion, they confirm that these difficulties are not due to the nature of GO but rather to the students' misrepresentations. According to their answers in Figure 2 to Figure 4, the majority of students think that the CL is lenses with thick edges and that the obtained image by the PM is real, 58\% of them believe that light propagates in the horizontal direction and it suffices to look at the object to see it (57\%); and to see themselves more in a mirror, it is necessary to move further away. These results seem similar to those found by [3, 24, 27, 30]. There are $90 \%$ students confirm that their representations are neither raised nor corrected; they add that they do not know the field of application of GO in their daily lives. The same case was also attested by the teachers, justifying this by a lack of didactic time and continuous training to their profits. These results confirm that during the SE/HE transition students are endowed with certain misrepresentations, which are completely opposed to physical laws and SC. Obviously, the students' misrepresentations do not promote a smooth transition; on the contrary, they may create GO difficulties for first-year university students.

According to the result of the testing given in Figure 5, we find that students have difficulties in GC. Indeed, $67 \%$ of them could not choose the correct answer relative to the GC of the image by a PM (Figure 5a). Another difficulty is reported in the dispersion of light by a rectangular prism (Figure 5b). 50\% of students believe that the ray that penetrates perpendicularly into the rectangular prism will continue its journey without any refraction; they also have difficulty identifying the symbols and functions of CLs. These results lead to deduce that students lack prerequisites concerning the form and the characteristics of the lenses. This finding is similar to that reported by [13]. Researchers also note from their answers that students understand the importance of light in vision. $80 \%$ of them have confirmed that they cannot see in a dark room; however, they have problems with the role and function of the eye in vision. This result seems consistent with that found by $[8,47]$. Another problem that appears among students concerns the recognition of the correct formula of the laws most used in GO like that of Descartes' 2nd Law of refraction and the relations of conjugation. These results show that students arrive at university with a low level of prerequisites. This low level, which is not evaluated from the HE teachers' responses collected in Table 1, leads us to blame the discontinuity of the GO program at the level of the two secondary levels (middle school and qualifying school). Indeed, according to the PS curriculum, this course is programmed in the second-year middle school; yet, it neither appears in the program of the third year of the same level nor in the common 
core syllabus of the qualifying levels, it is programmed in the first-year bac and it is even classified at the end of the curriculum. This poor classification of GO confirmed by the SE teachers and the absence of GO evaluation in the regional examination make students disinterested in this discipline. Thus, the only prerequisites remained for students are those built-in middle schools, and this is exactly what has been justified by $65 \%$ of students who have confirmed that they have not received the GO course in the first-year bac. The teachers also confirmed that the SE curriculum is based on the didactic transposition of scholarly knowledge into teaching knowledge, but this transposition is not adopted at HE. This lack of continuity of the program between the two levels affects the quality of the prerequisites for students in their first year of HE by forgetting some required notions which constitute an obstacle to effective learning that favors only surface learning. These results seem identical to those found by Hassouny, et al. [45].

The traditional TMs a well as the insufficiency of PWs may also be incriminated in the fragility of prerequisites. For teachers, this is justified by a lack of continuous training for their benefit and insufficient didactic materials for PWs. They also add that the use of ICTs as an alternative is very limited. The limitation of these ICTs is also reported by [14]. Another problem added according to the teachers' is the lack of a professional coordination meetings between them so that they can discuss the contents of the program together and brush up on its latest reform which the majority of HE teachers are not aware of. In short, the fragility of the prerequisites among students does not favor a smooth transition and consequently makes the learning of GO more difficult in the first year of university.

\subsection{Students' responses after the learning of the GO course}

Figure 6 to Figure 8 illustrate the types of the students' answers of the three exercises. These exercises are proposed to evaluate the students' levels and representations after studying the GO course. The answers are regrouped under three categories in Figure 6 and Figure 7. On the other hand, Figure 8 shows only two categories.

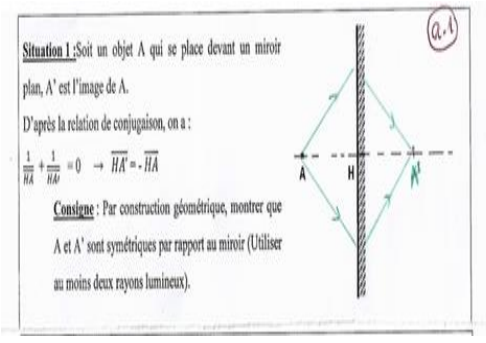

(a) Category 1

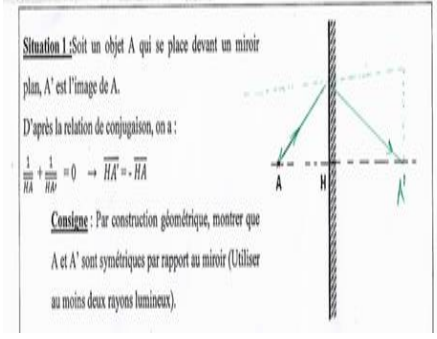

(b) Category 2

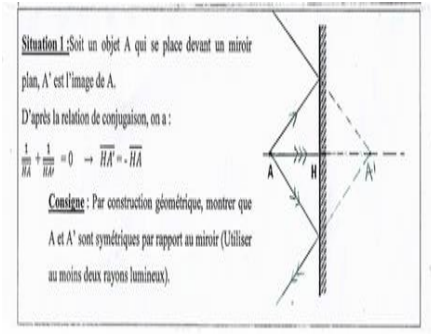

(c) Category 3

Figure 6. The students' responses of exercise 1 about the GC of the image of an object by a PM

Analysis of the responses mentioned in Figure 6 shows that the majority of students were able to find the image by applying the law given (the conjugation relations) in the statement of the exercise; on the other hand, they could not find it by GC. Indeed, they did not manage to construct geometrically the image of an object by a PM because they could neither distinguish between the real and the virtual image nor differentiate between the incident and reflected ray. These difficulties do not favor in the case of our sample learners, understanding the principle of image formation by mirror reflection, which has also been proved by $[11,19]$.

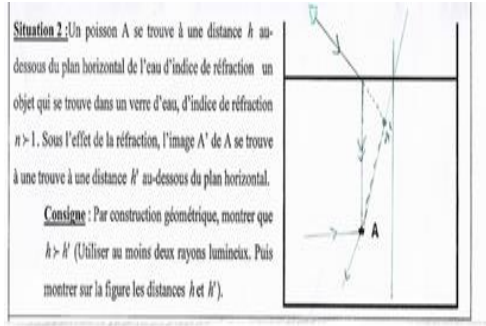

(a) Category 1

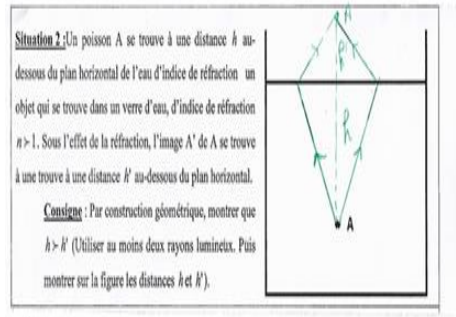

(b) Category 2

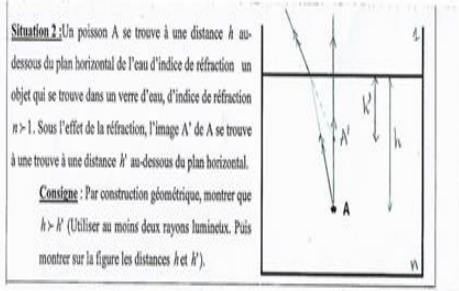

(c) Category 3

Figure 7. The students' responses of exercise 2 about the GC of the image of an object in water 
According to the responses illustrated in Figure 7, only two students could give the correct answer concerning the GC of the image of an object in water. The majority of them have traced the incident ray emitted by the eye, which confirms that their misrepresentations persist even after the learning of the GO course. These results seem similar to those found by $[14,19]$. The students cannot assimilate the fact that two different environments have two different refractive indices, and they do not also master the difference between the incident rays and those refracted; they cannot understand that the position of the image depends on the viewing angle, independently of Gauss conditions.

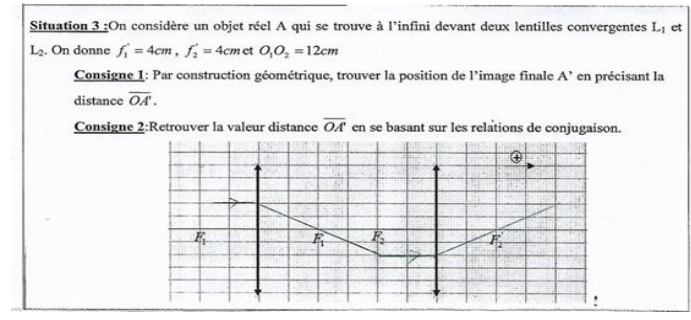

(a) Category 1

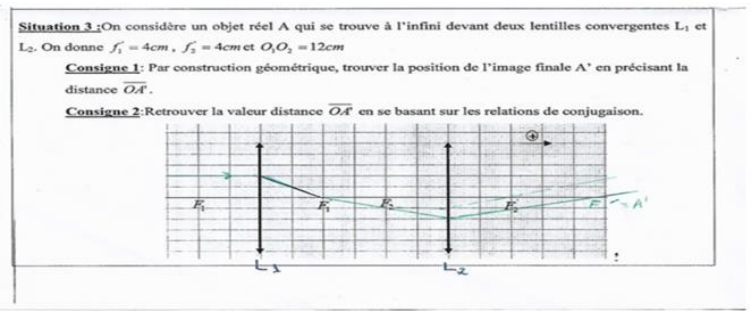

(b) Category 2

Figure 8. The students' responses of exercise 3 about the GC of an image of an object located at infinity in front of two CLs

Another difficulty is raised. It is about the GC of the image of an object by CL. This finding was confirmed by $[13,27]$. The same difficulty was observed during the research of the image of an object located at infinity in front of two CLs. According to the responses collected in Figure 8, the majority of students use a single particular ray to construct the image, which leads to the inference that they are unable to consider the cases of particular rays uses and those of non-particular rays. On the other hand, they can find this image by using conjugation relations.

It is worth noting that students after learning the course have a similar understanding of light. Yet, they still encounter difficulties in GC as they do not understand the basic principle of image formation and this is what has been demonstrated by $[11-13,34]$. The researchers also observe the persistence of the misrepresentations among them. These problems that persist are not linked, according to the responses of the actors of our investigation, to the nature of this discipline but to a break in the TMs between the two levels of education. It is also linked to a discontinuity of the program between the two levels of SE, to the insufficiency of PWs, to a low level of prerequisites for integrating $\mathrm{HE}$ and to the misrepresentations during the SE/HE transition.

\section{CONCLUSION}

In this study, the researchers started from an observation of the GO difficulties experienced by students in their first year at university. These difficulties, source of repetition and dropping out phenomena in open access Moroccan institutions, did not leave us indifferent.We surveyed first year university students, $\mathrm{SE}$ and HE teachers, to search for the causes of these difficulties and their impact on the quality of the SE/HE transition.

The analysis of the exercises given to students after the course have revealed the persistence of the GO difficulties at HE and more particularly in GC. As for the responses collected before the course, it appears that learners are not well prepared to integrate $\mathrm{HE}$ and that their prerequisites leave something to be desired, This study also shows that there is a break in the curriculum and the TMs between the two levels of education along with the existence and persistence of the misrepresentations among students even after the GO course. These factors do not actually favor a good transition between SE/HE. To overcome the aforementioned difficulties and ensure a better transition, the following solutions are suggested: 1) HE teachers should take into consideration the students' misrepresentations before the beginning of teaching process and they ought to think of using best teaching strategies to help students gain a rich understanding of the GO concepts; 2) The adoption of an active TM is very important to improve students' critical thinking skills, overcome their misrepresentations, and develop strong prerequisites for a seamless transition; 3) Ensuring continuity of the GO program between the three teaching cycles; 4) Strengthening the teaching of GO through PWs in SE and HE; 5) Reducing the number of students in the lecture halls and reviewing the 
didactic time of program execution to ensure continuity in TMs between SE and HE; 6) Carrying out and ensuring permanent coordination between the actors of the SE and HE; 7) Scheduling continuous professional training for teachers to improve their teaching practices. These preliminary results deserve to be deepened. We envisage studies focusing on active practices in GO in SE with a follow-up during the transition to HE.

\section{REFERENCES}

[1] S. Sukarmin, D. Ratnasari, and S. Suparmi, "Profile Analysis of Students' Concept Understanding on Heat and Temperature," J. Educ. Learn. (EduLearn), vol. 12, no. 3, pp. 350-356, 2018, doi: 10.11591/edulearn.v12i3.6427.

[2] L. Trudel, C. Parent, and R. Auger, "Développement et validation d'un test mesurant la compréhension des concepts cinématiques en physique au secondaire," Mes. Éval. En Éducation, vol. 31, no. 1, pp. 93-120, 2014.

[3] K. Ravanis and Y. Papamichaël, "Procédures didactiques de déstabilisation du système de représentations spontanées des élèves pour la propagation de la lumière," Didaskalia, vol. 7, no 7, pp. 43-61, 1995.

[4] D. Malafosse, A. Lerouge, and J.-M. Dusseau, "Étude en inter-didactíque des mathématiques et de la physique de l'acquisition de la loi d'Ohm au collège: Changement de cadre de rationalité," Didaskalia, no 18, pp. 61-98, 2001.

[5] S. Boumghar, et al., "Enseignement-apprentissage du concept "force" et persistance des difficultés: Quelle influence mathématique?" Rev. Sci. Math. ICT Educ., vol. 6, no 2, pp. 63-81, 2012.

[6] M. Oldache and C.E. Khiari, "Problèmes didactiques liés à l'enseignement de la physique moderne à l'université," RADISMA, no. 5, 2010.

[7] H. Niedderer, M. Meheut, and A. Tiberghien, "Recherche et développement en didactique de la physique à l'université ; résultats et tendances," Didaskalia, no. 14, pp. 95-113, 1999.

[8] I. Galili and A. Hazan, "Learners' knowledge in optics: Interpretation, structure and analysis," Int. J. Sci. Educ., vol. 22, no. 1, pp. 57-88, Jan. 2000.

[9] P. Tao, "Developing understanding of image formation by lenses through collaborative learning mediated by multimedia computer-assisted learning programs," Int. J. Sci. Educ., vol. 26, no. 10, pp. 1171-1197, 2004.

[10] P. Colin and L. Viennot, "Using two models in optics: Students' difficulties and suggestions for teaching," Am. $J$. Phys., vol. 69, no. S1, pp. S36-S44, Jul. 2001.

[11] O. Frédéric and B. Boudaoné, "Teaching and learning in geometrical optics in Burkina Faso third form classes: Presentation and analysis of class observations data and students' performance," Br. J. Sci., vol. 5, no. 1, pp. 83-103, 2012.

[12] S. Bendall, F. Goldberg, and I. Galili, "Prospective elementary teachers' prior knowledge about light," J. Res. Sci. Teach., vol. 30, no. 9, pp. 1169-1187, Nov. 1993.

[13] G. Tural, "Cross-Grade Comparison of Students' Conceptual Understanding with Lenses in Geometric Optics," Int. Counc. Assoc. Sci. Educ., vol. 26, no. 3, pp. 325-343, 2015.

[14] K. Berrada, A. Bouazaze, A. Idrissi Jouicha, and A. Oueriagli, "Implémentation d'un apprentissage actif en cours d'optique à l'université," 2nd International Conference on PedagogicalApproaches and e-Learning, Fès, Morocco, 2016.

[15] N. Benjelloun, M. Alami, and G. Rebmann, "Expérimentation d'un atelier java d'optique géométrique (AJOG) en situation de résolution de problème," Bulletin de l'union des physiciens, vol 97, pp. 1613-1621, 2003.

[16] D. Courtillot and M. Ruffenach, Enseigner les sciences physiques: De la 3e à la terminale. Paris: Bordas, 2006.

[17] B. Djanette, F. Chafiqi, and D. Kendil, "Students Misconceptions about Light in Algeria," in Education and Training in Optics and Photonics, 2009. [Online]. Available: https://doi.org/10.1364/ETOP.2009.EMA5

[18] L. Viennot, Raisonner en physique (la part du sens commun). Paris, Bruxelles, De Boeck Université, 1996.

[19] C.-C. Chen and M.-L. Lin, "Developing a two-tier diagnostic instrument to assess high school students' understanding The formation of image by plane mirror," Proc. Natl. Sci. Counc., 2002, vol. 12, no. 3, pp. 106-121.

[20] T. Apostilides and N. Valanide, "Secondary school students' conceptions relating to motion under gravity," Sci. Educ. Int., vol. 19, no. 4, pp. 405-414, 2008.

[21] S. Aydin and P. U. Keles, "Establishment for misconceptions that science teacher candidates have about geometric optics," TOJNED Online J. New Horiz. Educ., vol. 2, no. 3, pp. 7-15, 2012.

[22] N. A. Tachoua, "Interactions enseignant-élèves et situations d'enseignement-apprentissage en optique géométrique," Ph.D. Dissertation, Université Lumière Lyon II, 2005.

[23] F. Goldberg and L. Mcdermott, "An investigation of student understanding of the real image formed by a converging lens or concave mirror," American Journal of Physics, vol. 55, no. 2, pp. 108-119, 1987.

[24] DS. Heywood, "Primary trainee teachers' learning and teaching about light: Some pedagogic implications for initial teacher training," International Journal of Science Education, vol. 27, no. 12, pp. 1447-1475, 2005.

[25] N. Selley, "Towards a phenomenography of light and vision," International Journal of Science Education, vol. 18, no. 7, pp. 837-846, 1996.

[26] L Viennot and F. Chauvet, "Two dimensions to analyze research-based teaching strategies," International Journal of Science Education, vol. 19, no. 10, pp. 1159-1168, 1997.

[27] Aİ. Şen, "Investigations of misconceptions and learning difficulties of elementary students on light vision and mirrors," H Journal of Education, vol. 25, pp. 176-185, 2003.

[28] W. Kaminski, "Optique élémentaire en classe de quatrième: raisons et impact sur les maitres d'une maquette d'enseignement," Doctoral Thesis, didactics of physics in higher education, University of Paris, Paris, 1991. 
[29] B. Berthelsen, "Students Naïve Conceptions in Life Science,” MSTA Journal, vol. 44, no. 1 (Spring'99), pp. 13-19, 1999.

[30] F. M Goldberg and L.C. McDermott, "Student difficulties in understanding image formation by a plane mirror," Phys. Teach., vol. 24, pp. 472-480, 1986.

[31] J. Palacios, F. Cazorla, and A. Madrid, "Misconception of geometric optics and their association with relevant educational variables," International Journal of Science Education, vol. 11, no. 3, pp. 273-286, 1989.

[32] I. Ghedamsi and I. Bloch, "Comment le cursus secondaire prépare-t-il les élèves aux études universitaires? Le cas de l'enseignement de l'analyse en Tunisie," Petit x, no. 69, pp. 7-30, 2005.

[33] D. Grenier and C. Payan, "Des "situations recherches" pour l'apprentissage des savoirs transversaux," Conference l'enseignement des mathématiques face aux défis de l'école et des communautés, University of Sherbrooke, Québec, Canada, 2006. [Online]. Available: http://emf.unige.ch/files/2814/5390/3967/EMF2006_GT6_Grenier.pdf

[34] H. Chang, et al., "Investigating Primary and Secondary Students' Learning of Physics Concepts in Taiwan," Int. J. Sci. Educ., vol. 29, no. 4, pp. 465-482, Mar. 2007.

[35] B. Andersson and F. Bach, "On Designing and Evaluating Teaching Sequences Taking Geometrical Optics as an Example," Science Education, vol. 89, no. 2, pp. 196-218, 2004.

[36] P. Suparno, Misconceptions \& Changes in the Concept of Physics Education (in Bahasa). Jakarta: PT. Grasindo, 2005.

[37] N. Douar, "Etude de l'optique géométrique dans l'enseignement secondaire: difficultés et conceptions des élèves, points de vue didactique et historique," Magister's Thesis, didactics of physics, ENS of Kouba, Algeria, 2002.

[38] Y. Fahmi, D. Markus, and K, Sentot, "Development of diagnostic and remedial program-based interactive multimediato reduce student's misconceptions on geometric optics," Proc. Int. Conf. Math. Sci. Educ., University of Mataram 2015 Lombok Island, Indonesia, Nov. 4-5, 2015.

[39] L.C. Mcdermott, "Bridging the gap between teaching and learning: The role of research," AIP Conference Proceedings, 1997, pp. 139-166.

[40] N. D. S. Chetty, et al., "Learning styles and teaching styles determine students' academic performances," International Journal of Evaluation and Research in Education (IJERE), vol. 8, no. 3, pp. 610-615, 2019.

[41] E. Töre, "The opinions of students, professors and practice teachers on the teaching practice course," International Journal of Evaluation and Research in Education (IJERE), vol. 9, no. 1, pp. 10-20, 2020.

[42] ALJ. Omar and N. Benjelloun, "Intégration des TIC dans l'enseignement des sciences physiques au Maroc dans le cadre du programme GENIE: difficultés et obstacles," International Journal of Technologies in Higher Education, vol. 10, no. 2, pp. 49-65, 2013.

[43] P. U. Osadebe, et al., "Undergraduate business education students' perception on information and communication technology use in teaching and learning," International Journal of Evaluation and Research in Education (IJERE), vol. 9, no. 2, pp. 359-363, 2020.

[44] Z. Mansouri and M. E. A. Moumine, "Primary and Secondary Education in Morocco: From Access to School into Generalization to Dropout," International Journal of Evaluation and Research in Education (IJERE), vol. 6, no. 1, pp. 9-16, 2017, doi: 10.11591/ijere.v6i1.6341.

[45] E. Hassouny, F. Kaddari, A. Elachqar, I. Habibi, and B. Hassan, "Le groupe de discussion, la technique du groupe nominale et le questionnaire : méthodes de diagnostic des obstacles en optique géométrique au secondaire," Am. $J$. Innov. Res. Appl. Sci., vol. 2, pp. 363-371, 2016.

[46] A. Khalid, L. Ajana, A. Mokri, and A. Chikhaoui, "Préparation de l'expérimentation d'un logiciel d'optique géométrique: Pretest de diagnostic de difficultés d'élèves de baccalauréat sciences expérimentales," 2019.

[47] M.Ronen and B. Eylon, "To see or not to see: the eye in geometrical optics - when and how?" Physics Education, vol. 28, pp. 52-59. 1993.

[48] H. Bouabid, et al., "L'enseignement supérieur au Maroc, Efficacité, efficience et défis du système universitaire à accès ouvert," Report of the Higher Council for Education, Training and Scientific Research, Rabat, Morocco, 2018.

[49] S. Duval and C. Bouchard, "Transition de l'élève de l'éducation préscolaire vers l'enseignement primaire," Nouveaux cahiers de la recherche en éducation, vol. 16, no. 2, pp. 147-181, 2013.

[50] A. Barro and F. Ouattara, "Problématique de la transition enseignement secondaire - enseignement supérieur Quelques causes des échecs en physique et en chimie des étudiants de première année des universités du Burkina Faso," Bul Union Phys, vol. 102, no. 905, pp. 837-845, 2008.

[51] D. Maurice, "Réussir la première année à l'université. La transition Secondaire-Université: le projet Boussole," Rev. Fr. Pédagogie, vol. 136, no. 1, pp. 77-86, 2001.

[52] B. Nachit, et al., "La transition lycée -Université en mathématiques: Cas de l'enseignement de l'analyse au Maroc," Rev. Sci. Int. L'Education Form., vol. 3, no. 6, 2018. 